\title{
Postoperative Radiotherapy after Radical Prostatectomy: Indications and Open Questions
}

\author{
Pirus Ghadjar, ${ }^{1}$ Daniel Zwahlen, ${ }^{2}$ Daniel M. Aebersold, ${ }^{1}$ and F. Zimmermann ${ }^{3}$ \\ ${ }^{1}$ Department of Radiation Oncology, Inselspital, Bern University Hospital, University of Bern, Freiburgstrasse, \\ 3010 Bern, Switzerland \\ ${ }^{2}$ Department of Radiation Oncology, Kantonsspital Graubünden, 7000 Chur, Switzerland \\ ${ }^{3}$ Department of Radiation Oncology, University Hospital Basel, 4031 Basel, Switzerland \\ Correspondence should be addressed to Daniel Zwahlen, daniel.zwahlen@ksgr.ch
}

Received 15 July 2011; Revised 14 December 2011; Accepted 15 December 2011

Academic Editor: Jay P. Ciezki

Copyright (๑) 2012 Pirus Ghadjar et al. This is an open access article distributed under the Creative Commons Attribution License, which permits unrestricted use, distribution, and reproduction in any medium, provided the original work is properly cited.

Biochemical relapse after radical prostatectomy occurs in approximately $15-40 \%$ of patients within 5 years. Postoperative radiotherapy is the only curative treatment for these patients. After radical prostatectomy, two different strategies can be offered, adjuvant or salvage radiotherapy. Adjuvant radiotherapy is defined as treatment given directly after surgery in the presence of risk factors (R1 resection, pT3) before biochemical relapse occurs. It consists of 60-64 Gy and was shown to increase biochemical relapse-free survival in three randomized controlled trials and to increase overall survival after a median followup of 12.7 years in one of these trials. Salvage radiotherapy, on the other hand, is given upon biochemical relapse and is the preferred option, by many centers as it does not include patients who might be cured by surgery alone. As described in only retrospective studies the dose for salvage radiotherapy ranges from 64 to $72 \mathrm{~Gy}$ and is usually dependent on the absence or presence of macroscopic recurrence. Randomized trials are currently investigating the role of adjuvant and salvage radiotherapy. Patients with biochemical relapse after prostatectomy should at the earliest sign of relapse be referred to salvage radiotherapy and should preferably be treated within a clinical trial.

\section{Introduction}

Radical prostatectomy (RP) provides excellent cancer control in patients with localized prostate cancer. However, half of all patients present with one or more risk factors for recurrent disease including higher Gleason Score, extracapsular extension (TNM tumor classification pT3a), invasion of the seminal vesicles (pT3b), or positive resection margins (R1). As a result, the risk of biochemical relapse is approximately 15-40\% 5 years after RP $[1,2]$ and still increasing later [3] with even higher significance for patients with initially markedly elevated prostate-specific antigen (PSA) values [4, 5]. In patients with biochemical relapse, median time to bone metastasis is 8 years [6]. It is more pronounced with PSA doubling time of $<12$ months, resulting in a 5-year metastatic progression-free survival of less than 20\% [7]. From several trials, nomograms have been created to assess the risk of an individual patient for tumor progression $[8,9]$.
This documents the importance of adequate selection of men after curative intended local treatment of prostate cancer.

Postoperative radiotherapy (RT) can be performed directly after RP based on risk factors (adjuvant RT), or it is performed in case of biochemical relapse after RP or in patients who have persistently detectable PSA levels postoperatively (salvage RT). Three randomized controlled trials investigating the role of adjuvant RT demonstrated improved biochemical control rates [10-12], whereas metastasis-free survival and overall survival were improved in only one trial after 12.7 years of followup [13]. In contrast, to date, improved biochemical control for salvage RT has been shown only in retrospective studies.

Despite the lower level of evidence, salvage RT in patients with biochemical recurrence as compared to adjuvant RT in all high-risk patients may avoid side effects in at least a subgroup of patients being already cured by surgery alone and is therefore the preferred postoperative treatment option 
in many centers. Five years after RP approximately $45-54 \%$ of patients with risk factors remain without evidence of disease without adjuvant RT. This can be estimated from the control arms of the three randomized adjuvant RT trials [1012]. This paper will provide recommendations regarding the management of prostate cancer patients, who either have risk factors for recurrence or already established biochemical relapse after RP.

\section{Materials and Methods}

Data for this paper were identified by searches of MEDLINE, Current Contents, PubMed, and references from relevant articles using medical subject headings including prostate cancer, postoperative, radiotherapy, adjuvant, and salvage.

\section{Results and Discussion}

3.1. Adjuvant Radiotherapy. Three randomized phase III trials have addressed the benefit of adjuvant RT to the prostatic bed in an immediate postoperative period [10-12]. The studies are summarized in Tables 1 and 2 as well as below. Two trials have been initiated in the late eighties and early nineties of the last century, using old $2 \mathrm{D}$ radiation techniques, and none of these trials provided details of the performed lymph node dissection. Additionally, two out of three trials allowed the inclusion of patients with postoperatively elevated PSA values beyond $0.2 \mathrm{ng} / \mathrm{mL}$, which nowadays is defined as PSA recurrence and therefore represents early salvage RT as compared to adjuvant RT. Therefore, data and discussion of these trials have to be interpreted carefully, and can only be transferred into modern radiation oncology with caution.

3.2. EORTC 22911 Trial. The European Organisation for the Research and Treatment of Cancer (EORTC) trial 22911 [10] included 1005 patients between 1992 and 2001 either having had pT3a, pT3b, or R1. Patients were randomized to undergo either RT to the prostatic fossa to a dose of $60 \mathrm{~Gy}$ at a median time of 90 days after surgery or observation, respectively. The primary endpoint was biochemical progression-free survival (bPFS). Biochemical relapse was defined as a PSA $\geq$ $0.2 \mathrm{ng} / \mathrm{mL}$ above postoperative nadir. Initial results were published after a median followup of 5 years in 2005. Postoperative RT demonstrated a significant improvement in bPFS compared to observation ( $74 \%$ versus $52.6 \%$, hazard ratio (HR) $0.48,98 \%$ confidence interval (CI) $0.37-0.62$; $P<0.0001)$. There was also a significant reduction in the cumulative incidence of locoregional recurrence at 5 years of $5.4 \%$ in the RT arm and $15.4 \%$ in the observation arm, respectively $(P<0.0001)$.

In conclusion, this trial provided strong evidence that adjuvant RT improved bPFS and local tumour control. Subgroup analysis after a central pathology review demonstrated that patients with positive resection margins benefitted most from adjuvant RT [14]. But this conclusion was only achieved by a detailed central pathological review, emphasizing the disagreement both on the detection of positive margins and definition of differentiation of the tumor by different pathologists. Treatment was well tolerated. There was no late grade 4 toxicity reported and the 5-year actuarial incidence of late grade 3 toxicity was $4.2 \%$ in the RT group and $2.6 \%$ in the observation arm $(P=0.07)$.

3.3. SWOG 8794 Trial. The Southwest Oncology Group (SWOG) 8794 trial [11] included 425 pT3a, pT3b or R1 patients between 1988 and 1997. Patients received either adjuvant RT to the prostatic fossa with 60-64 Gy or were observed. Postoperative PSA values were available for 376 patients $(88 \%)$, and $33.8 \%$ of patients had PSA values of $0.2 \mathrm{ng} / \mathrm{mL}$ and above. Primary trial endpoint was metastasisfree survival. After a median followup of 12.7 years [13], adjuvant RT improved the median metastasis-free survival for 1.8 years (HR $0.71,95 \%$ CI $0.54-0.94 ; P=0.016$ ) as well as the median overall survival for 1.9 years (HR $0.72,95 \% \mathrm{CI}$ $0.55-0.96 ; P=0.023)$, respectively. There was no subgroup in the subset analysis on seminal vesicle infiltration, Gleason Score, or postoperative PSA value without an improvement by adjuvant RT. However, patients with a postoperative PSA $>0.2 \mathrm{ng} / \mathrm{mL}$ had a significantly higher risk for metastasis and death $(P=0.03)$, although the relative improvement of immediate postoperative irradiation was still the same. This stresses the value of early adjuvant RT before development of PSA recurrence. In contrast, it may also support the idea that there are risk factors for tumor progression which cannot be influenced by RT. Unfortunately clinical outcome of the subgroup of patients in the observational arm who ultimately received salvage RT for either increasing PSA or a local recurrence (70 patients, mean PSA value $1.0 \mathrm{ng} / \mathrm{mL}$ ) is not provided. This would allow to further characterize the effect of delayed postoperative RT. Adjuvant RT was well tolerated; however, urinary incontinence was more common after RT $(6.5 \%)$ compared to observation $(2.8 \%)(P=$ 0.11 ), and rectal complications including proctitis and rectal bleeding were only present in the RT arm $(3.3 \%$ versus $0 \%$, $P=0.02)$. In the initial analysis, the incidence of urethral strictures was significantly higher in the RT arm $(17.8 \%)$ as compared to the observation arm $(9.5 \%)(P=0.02)[11]$. In contrast, adjuvant RT did not negatively impact erectile dysfunction [15].

3.4. ARO 96-02/AUO AP 09/05 Trial. The "Arbeitsgemeinschaft Radiologische Onkologie (ARO) und Urologische Onkologie (AUO)" of the German Cancer Society included 388 pT3-4pN0M0 patients into the trial [12]. As an unique inclusion criteria, all 266 eligible and evaluable patients had undetectable PSA $(<0.1 \mathrm{ng} / \mathrm{mL})$ postoperatively. RT of the prostatic fossa with $60 \mathrm{~Gy}$ was compared to observation. Primary trial endpoint was progression-free survival (PFS) defined as two consecutive PSA raises above the detection limit of the test used, local or distant recurrence, or death. The PFS rates, based on a median followup of 53.7 months, were significantly improved in the adjuvant RT arm compared to observation $(72 \%$ versus $54 \%$, HR $0.53,95 \%$ CI $0.37-0.79 ; P=0.0015)$. In an unplanned subgroup analysis, positive resection margins, absence of seminal vesicle 
TABLE 1: Characteristics of randomized trials on immediate adjuvant RT.

\begin{tabular}{|c|c|c|c|}
\hline Trial & SWOG 8794 & EORTC 22911 & ARO 96-02 \\
\hline Year of initiation & 1988 & 1992 & 1996 \\
\hline \multicolumn{4}{|l|}{ Pats. } \\
\hline Randomized & 431 & 1005 & 307 from 385 selected \\
\hline Eligible & 425 & 968 & 266 \\
\hline Percent & $98.6 \%$ & $96.3 \%$ & $87.3 \%$ \\
\hline Median age & 64.5 years & 65 years & 64 years \\
\hline \multirow{4}{*}{ Inclusion criteria } & $\begin{array}{l}\text { cT1-2, post-RP: } \\
\text { Extraprostatic extension and/or } \\
\text { seminal vesicle invasion and/or } \\
\text { positive resection margins }\end{array}$ & $\begin{array}{l}\text { Extraprostatic extension and/or } \\
\text { seminal vesicle invasion and/or } \\
\text { positive resection margins }\end{array}$ & $\begin{array}{l}\text { cT1-3, post-RP: } \\
\text { Extraprostatic extension } \\
\text { and/or seminal vesicle } \\
\text { invasion }\end{array}$ \\
\hline & $\begin{array}{l}\text { pT3 and/or R1, c/p N0 ( } 97 \% \text { pelvic } \\
\text { LN-dissection) cM0 }\end{array}$ & $\begin{array}{l}\text { pT2 R1 or pT3 R0-1, c/p N0 (99\% } \\
\text { pN0) cM0 }\end{array}$ & pT3-4 R0-1 pN0 cM0 \\
\hline & SWOG PS 0-2 & WHO PS 0-1 & WHO PS 0-1 \\
\hline & Age not reported & Age $<76$ years & Age $<76$ years \\
\hline Postop. PSA & $\begin{array}{l}<0.2 \mathrm{ng} / \mathrm{mL}: 66.2 \% \\
\geq 0.2 \mathrm{ng} / \mathrm{mL}: 33.8 \%\end{array}$ & $\begin{array}{l}\leq 0.2 \mathrm{ng} / \mathrm{mL}: 88.7 \% \\
>0.2 \mathrm{ng} / \mathrm{mL}: 10.7 \% \\
\text { Unknown: } 0.6 \%\end{array}$ & $<0.1 \mathrm{ng} / \mathrm{mL}: 100 \%$ \\
\hline Stratification & $\begin{array}{l}\text { Positive margins or capsule invasion } \\
\text { versus invasion of seminal vesicles } \\
\text { versus positive margins and capsule } \\
\text { invasion; HT }\end{array}$ & $\begin{array}{l}\text { Institution; capsule invasion; positive } \\
\text { margins; invasion of the seminal } \\
\text { vesicles }\end{array}$ & $\begin{array}{l}\text { Gleason Score; resection } \\
\text { margins; neoadjuvant HT; } \\
\text { tumor stage }\end{array}$ \\
\hline Hormonal therapy & $8.5 \%$ & $10.0 \%$ & $11.5 \%$ \\
\hline Adjuvant RT & $30-32 \times 2.0 \mathrm{~Gy}$ & $30 \times 2.0$ Gy $($ in $90.8 \%)$ & $30 \times 2.0$ Gy (in $82 \%)$ \\
\hline Time from RP to RT & $<18$ weeks & $<16$ weeks & 10-30 weeks \\
\hline $\begin{array}{l}\text { Treatment in } \\
\text { observation arm }\end{array}$ & RT: $33.2 \%$ & $\begin{array}{l}\text { RT: } 22.5 \% \\
\text { HT: } 9.1 \% \\
\text { Other: } 1 \% \\
\end{array}$ & Not reported \\
\hline Median followup & 12.6 years & 5 years & 4.5 years \\
\hline Primary endpoint & $\begin{array}{l}\text { Metastasis-free survival (bone, } \\
\text { visceral, extrapelvic lymph nodes) }\end{array}$ & Biochemical progression-free survival & Progression-free survival \\
\hline Definition of bNED & $\begin{array}{l}\text { PSA }>0.4 \mathrm{ng} / \mathrm{mL} \text { for postop. } \\
\text { PSA }<0.4 \mathrm{ng} / \mathrm{mL}\end{array}$ & $\begin{array}{l}\text { PSA }>0.2 \mathrm{ng} / \mathrm{mL} \text { above lowest postop. } \\
\text { PSA }\end{array}$ & 2 increasing PSA values \\
\hline
\end{tabular}

bNED: biological no evidence of disease; RP: radical prostatectomy; RT: radiotherapy; HT: hormonal therapy; PS: performance status.

invasion, and a preoperative PSA $>10 \mathrm{ng} / \mathrm{mL}$ defined populations with a nominally significantly proven efficacy of RT, irrespective of the tumors differentiation. The toxicity rates were low. No patient experienced grade 4 toxicity. Two patients in the RT arm developed a urethral stricture.

3.5. Salvage Radiotherapy. Whereas an increase of PSA after $\mathrm{RP}$ of a nonorgan confined cancer can be seen in approximately $15-40 \%$, a pure local recurrence is predominant with a slow slope of PSA ( $>1$ year after resection; PSA doubling time $>12$ months; PSA increase within 12 months $<0.75 \mathrm{ng} /$ $\mathrm{mL}$ ), a better differentiated cancer (Gleason Score $<8$ ), positive margins, and negative pelvic lymph nodes $[9,16]$. Outside of clinical trials, a precipitated start of hormonal therapy can be avoided at least for patients carrying all favourable risk factors (PSA $<2.0 \mathrm{ng} / \mathrm{mL}$, Gleason Score 4-7, positive resection margins, PSA doubling time $>12$ months) $[9,17]$. Thereby, the distinction of local versus systemic tumor progression is not compromised, and additional side effects can be avoided. So far, the combination of postoperative
RT and hormonal therapy has not been shown to improve overall survival as compared to postoperative RT alone [9, 17]. Taking this into account, the authors are sceptic on the value of the recent EORTC trial (NCT00949962) on adjuvant RT in stage I-III prostate cancer, randomizing 6 months of hormonal therapy in addition to adjuvant RT to analyze its impact on bPFS. If hormonal therapy is involved, overall survival seems to be a more appropriate endpoint. In principle, by irradiation, the PSA can by decreased to nonmeasurable values in up to $50 \%$ of the cases at 5 -year followup $[9,18]$. The observation from large retrospective trials as well as from the randomized trials of SWOG and EORTC suggests the need to start salvage RT at the earliest sign of biochemical failure, with PSA value being between 0.2 and $0.5 \mathrm{ng} / \mathrm{mL}$ [18-20]. The development of a measurable local recurrence should be avoided, because in these patients outcome after salvage RT seems to be worse $[18,21,22]$. Unfortunately, there are only retrospective studies available addressing the benefit of salvage RT (Table 3 ). Trock et al. analyzed 635 patients undergoing RP in the years of 1982 to 
TABLE 2: Results of randomized trials on immediate adjuvant RT.

\begin{tabular}{|c|c|c|c|}
\hline Trial & SWOG 8794 & EORTC 22911 & ARO 96-02 \\
\hline Overall survival & $\begin{array}{c}\text { HR: } 0.72 \\
(95 \% \text { CI } 0.55-0.96) \\
P=0.023\end{array}$ & $\begin{array}{c}\text { HR: } 1.09 \\
(98 \% \text { CI } 0.67-1.79) \\
P=0.68\end{array}$ & Not reported \\
\hline bNED & $\begin{array}{c}\text { HR: } 0.43 \\
(95 \% \text { CI } 0.31-0.58) \\
P<0.001\end{array}$ & $\begin{array}{c}\text { HR: } 0.48 \\
(98 \% \text { CI } 0.37-0.62) \\
P<0.0001\end{array}$ & 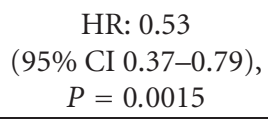 \\
\hline Metastasis-free survival & $\begin{array}{c}\text { HR: } 0.71 \\
(95 \% \text { CI } 0.54-0.94) \\
P=0.016\end{array}$ & Not reported & $\begin{array}{l}98 \% \text { versus } 95.1 \% \\
\text { (n.s.) }\end{array}$ \\
\hline $\begin{array}{l}\text { Clinical progression-free } \\
\text { survival }\end{array}$ & $\begin{array}{c}\text { HR: } 0.62 \\
(95 \% \text { CI } 0.46-0.82) \\
P=0.001\end{array}$ & $\begin{array}{c}\text { HR: } 0.61 \\
(98 \% \text { CI } 0.43-0.87) \\
P=0.0009\end{array}$ & Not reported \\
\hline $\begin{array}{l}\text { Time to initiation of } \\
\text { hormonal therapy }\end{array}$ & $\begin{array}{c}\text { HR: } 0.45 \\
(95 \% \text { CI } 0.29-0.68) \\
P<0.001\end{array}$ & Not reported & Not reported \\
\hline Overall toxicity & $\begin{array}{c}23.8 \% \text { versus } 11.9 \% \\
P=0.002\end{array}$ & $\begin{array}{l}4.2 \% \text { versus } 2.6 \% \\
(\text { Grade } 3 ; P=0.07)\end{array}$ & $\begin{array}{c}21.9 \% \text { versus } 3.7 \% \\
P<0.0001\end{array}$ \\
\hline Rectal toxicity & $\begin{array}{c}3.3 \% \text { versus } 0 \%, \\
P=0.02\end{array}$ & Not reported & $1.4 \%$ versus $0 \%$ \\
\hline Urinary stricture & $\begin{array}{c}17.8 \% \text { versus } 9.5 \% \\
P=0.02\end{array}$ & Not reported & Not reported \\
\hline Total urinary incontinence & $\begin{array}{c}6.5 \% \text { versus } 2.8 \%, \\
P=0.11\end{array}$ & Not reported & Not reported \\
\hline
\end{tabular}

HR: hazard ratio; CI: confidence interval; n.s.: not significant.

2004 who experienced biochemical and/or local recurrence and received either no salvage treatment $(n=397)$, salvage RT alone $(n=160)$, or salvage RT combined with hormonal therapy $(n=78)$, respectively [17]. Median dose was 66.5 Gy for patients with salvage RT and 67.2 Gy for patients receiving salvage $\mathrm{RT}$ and hormonal therapy. After a median followup of 6 years, salvage RT alone was associated with a 3 -fold increase in prostate-cancer-specific survival compared to those with no salvage treatment (HR 0.32, 95\% CI 0.19 $0.54 ; P<0.001)$. Use of hormonal therapy was not associated with additional increase in prostate-cancer-specific survival. The increase in prostate cancer-specific survival associated with salvage RT was most marked in men with a PSA doubling time of less than 6 months and in patients with a Gleason Score of 8-10. This is an important finding as it suggests that patients with prostate cancer and adverse risk factors profit most from salvage RT. It is in contrast to other data, emphasizing the higher probability of a local tumor growth with long PSA doubling time and better differentiated cancer, and therefore a better and longer lasting effect on biochemical control $[23,24]$. Therefore, until results from randomized trials become available, it seems not justifiable to refuse the admittance of salvage RT to any subgroup of patients.

A large multi-institutional retrospective study by Stephenson et al. analyzed 1540 patients who underwent salvage RT for biochemical relapse between 1987 and 2005 [9]. The primary study endpoint was defined as disease progression after salvage RT with PSA value $\geq 0.2 \mathrm{ng} / \mathrm{mL}$ above post-RT nadir, initiation of systemic therapy, or clinical progression.
A total of 214 patients (14\%) received neoadjuvant and/or concurrent hormonal therapy for a median duration of 4.1 months. Median RT dose was $64.8 \mathrm{~Gy}$. The median followup was 53 months. Overall, the 6-year progression-free probability (PFP) after salvage RT was 32\%. However, when analyzed according to PSA levels at initiation of treatment, an estimated $48 \%$ who received salvage RT without hormonal therapy at a PSA level $\leq 0.50 \mathrm{ng} / \mathrm{mL}$ were disease-free at 6 years compared to $40 \%, 28 \%$, and $18 \%$ of those treated at PSA levels of $0.51-1.00,1.01-1.50$, and greater than $1.50 \mathrm{ng} / \mathrm{mL}$, respectively. These results suggested the need for salvage RT at the earliest sign of biochemical relapse after RP. The 4-year PFP estimates after salvage RT alone were still improved in patients with high-risk features such as PSA $\geq 2 \mathrm{ng} / \mathrm{mL}$ before salvage RT, Gleason Score of $8-10$, and PSA doubling time of $\leq 10$ months $[9,24]$. However, data from randomized controlled trials are lacking.

Overall, most clinical data support that a high percentage of patients with rising PSA after RP have a local recurrence. RT to the prostatic bed alone allows long lasting tumor control, avoiding the toxicity of pelvic lymphatic irradiation and additional hormonal therapy as well. It seems reasonable to follow the guidelines on target volume definition from the EORTC Radiation Oncology Group, to reach an optimal compromise on both target volume coverage and sparing of critical organs and structures at risk. For the authors, it is a prerequisite to use such guidelines not only for participating in clinical trials on prostate cancer, but when highly sophisticated modern RT techniques with steep dose decrease close 
TABLE 3: Characteristics and results of retrospective reports on salvage RT.

\begin{tabular}{|c|c|c|c|c|c|c|c|c|}
\hline First author & Year & No. Pats. & $\begin{array}{c}\text { Median } \\
\text { pre-RT-PSA } \\
(\mathrm{ng} / \mathrm{mL})\end{array}$ & HT (\%) & $\begin{array}{c}\text { Med. } \\
\text { RT-dose } \\
(\mathrm{Gy})\end{array}$ & RT technique & $\begin{array}{l}\text { Followup } \\
\text { (months) }\end{array}$ & bNED (\%) \\
\hline Anscher et al. [25] & 2000 & 89 & 1.4 & 9 & 66.0 & $2 \mathrm{D} / 3 \mathrm{D}$ & 48 & 50 (4 y.) \\
\hline Bernard et al. [26] & 2010 & 364 & 0.6 & 0 & 64.8 & $2 \mathrm{D} / 3 \mathrm{D}$ & 72 & $50(5 \mathrm{y})$. \\
\hline De Meerleer et al. [27] & 2008 & 87 & 0.7 & 56 & 75.0 & IMRT & 30 & 67 (5 y.) \\
\hline Do et al. [28] & 2002 & 73 & 2.8 & 9 & 64.8 & $2 \mathrm{D}$ & 42 & 45 (10 y.) \\
\hline King and Spiotto [29] & 2008 & 84 & 0.45 & 57 & 70.0 & $2 \mathrm{D} / 3 \mathrm{D} / \mathrm{IMRT}$ & $>60$ & $58(5 \mathrm{y})$. \\
\hline Loeb et al. [30] & 2008 & 107 & $\sim 0.7$ & 0 & 63.0 & IMRT & 53 & 55 (7y.) \\
\hline MacDonald et al. [22] & 2004 & 102 & 1.1 & 0 & 65.8 & n.r. & 50 & $38(5 \mathrm{y})$. \\
\hline Neuhof et al. [20] & 2007 & 171 & 1.1 & 29 & $60-66$ & $3 \mathrm{D}$ & 39 & 35 (5 y.) \\
\hline Pazona et al. [31] & 2005 & 223 & 0.8 & 4.5 & 63 & $3 \mathrm{D}$ & 56 & 40 (5 y.) \\
\hline Pisansky et al. [32] & 2000 & 166 & 0.9 & 4 & 64.0 & $2 \mathrm{D} / 3 \mathrm{D}$ & 52 & 46 (5y.) \\
\hline Stephenson et al. [24] & 2004 & 501 & 0.7 & 17 & 64.8 & $2 \mathrm{D} / 3 \mathrm{D} / \mathrm{IMRT}$ & 45 & 45 ( 4 y.) \\
\hline Stephenson et al. [9] & 2007 & 1540 & 1.1 & 14 & 64.8 & $2 \mathrm{D} / 3 \mathrm{D} / \mathrm{IMRT}$ & 53 & 32 (6 y.) \\
\hline Trock et al. [17] & 2008 & 160 & 0.7 & 0 & 66.5 & $2 \mathrm{D} / 3 \mathrm{D}$ & 72 & 89 (10 y. OS) \\
\hline Van Der Poel et al. [33] & 2008 & 41 & 2.15 & 7 & $60-70$ & n.r. & 73 & 44 (10 y.) \\
\hline Wiegel et al. [19] & 2009 & 162 & 0.33 & 0 & 66.0 & $3 \mathrm{D}$ & 41 & 54 (3.5 y.) \\
\hline
\end{tabular}

RT: radiotherapy; HT: hormonal therapy; Med. RT dose: median total dose of radiation therapy; bNED: biochemical no evidence of disease; n.r.: not reported; 2 D: 2-dimensional treatment planning; 3D: 3-dimensional treatment planning; IMRT: intensity-modulated radiation therapy; OS: overall survival.

to the margins of the planning target volume are being used, in order to prevent out volume or marginal local recurrences [34].

3.6. Effect of Dose Escalation. In accordance with the welldescribed dose-escalation trials for primary RT of localized prostate cancer [35], it has recently been proposed that dose intensification either for salvage RT $[29,36]$ or adjuvant RT [37] would be more effective in terms of cancer control. From very recent retrospective reports, it became obvious that total doses of more than 66 Gy can be used safely when modern techniques are available $[26,27,29,36]$. Nevertheless, intensity-modulated RT to the prostate bed-up to 75 Gy was associated with 30\% late grade 2 genitourinary toxicity [27].

Also, it has been suggested that each Gy increase in total dose may improve the biochemical tumor control by more than 3\%, having doses between 64 and $70 \mathrm{~Gy}$ still in the steep part of the dose-response curve [29]. Therefore, a total dose towards 70 Gy might be considered in salvage situation, when the risk of severe toxicity can be minimized by using modern radiation techniques. In the absence of results from randomized trials, the potentially improved local tumor control by higher RT dose should be carefully weighted out against possibly increased toxicity. In principle, toxicity of salvage RT with total doses of about $70 \mathrm{~Gy}$ is low with less than $3 \%$ of late grade 3 proctitis or genitourinary side effects, respectively. [19, $27,33,38]$.

However, the dose-dependent effect has never been prospectively assessed both in the adjuvant or salvage setting. The Swiss Group for Clinical Cancer Research (SAKK) is conducting a randomized controlled international trial comparing salvage RT with $64 \mathrm{~Gy}$ and $70 \mathrm{~Gy}$ without hormonal therapy in patients with prostate cancer and biochemical relapse after RP (SAKK 09/10, NCT01272050). The trial will include men $\leq 75$ years with pT2-3 N0 R0-1, with a PSA of at least $\geq 0.1 \mathrm{ng} / \mathrm{mL}$ and rising but $\leq 2 \mathrm{ng} / \mathrm{mL}$. Patients with evidence of macroscopic recurrence or metastatic disease are excluded. It is estimated to enroll 350 patients, and the trial is currently recruiting patients. The primary endpoint is freedom from biochemical progression including a PSA of $\geq 0.4 \mathrm{ng} / \mathrm{mL}$ and rising and/or clinical failure. The trial will contain quality of life analysis, quality assurance of RT, and a central pathology review.

3.7. Adjuvant versus Salvage Radiotherapy. The advantages of immediate adjuvant RT are obvious from three randomised trials, achieving a biochemical control at 5 years of more than $20 \%$ higher than from salvage RT [10-12, 39]. Nevertheless, it has to be taken into account that in two out of three trials on adjuvant RT, more than $25 \%$ of the included patients had a PSA of more than $0.2 \mathrm{ng} / \mathrm{mL}$ at the initiation of RT which corresponds to a "salvage-like" situation $[10,11]$. Importantly, the alternative concept of salvage RT avoids treatment of patients without tumor progression after RP despite having risk factors such as $\mathrm{R} 1$ or $\mathrm{pT} 3 \mathrm{~b}$. The toxicity and morbidity of urethral stenosis and incontinence can be abstained by starting RT years after full recovery from RP.

There have been multiple retrospective clinical trials comparing the influence of either immediate adjuvant or salvage RT on local control and/or biochemical control [40]. Consistent improvements in both endpoints have been observed. The biochemical control at 5 years was approximately $69-89 \%$ for adjuvant and only $39-68 \%$ for salvage RT. Local control rates were higher than 95\% for adjuvant and 79-93\% for salvage treatment. Of course, this can be explained, at least in part, by a selection bias in favour of adjuvant RT, since 
it is known that roughly half of the patients who underwent adjuvant RT would not experience a PSA recurrence even without RT; moreover, the PSA values in the salvage situation are higher, indicating a higher tumor load demanding higher radiation doses.

Three randomized clinical trials are currently comparing the timing of RT to answer if immediate adjuvant policy will be any more effective than a salvage policy. The RADICALS (radiotherapy and androgen deprivation in combination after local surgery) trial (NCT00541047) conducted by the Medical Research Council (UK) and the National Cancer Institute of Canada Clinical trials Group aims to recruit 4000 patients; primary endpoint is 10 -year prostate-cancerspecific survival. The trial has two randomizations steps, one regarding the time of RT with a dose of $66 \mathrm{~Gy}$ to the prostatic fossa and one regarding use of combined six months hormonal therapy with postoperative RT.

The French Groupe d'Étude des Tumeurs Uro-Génitales (GETUG) has activated the GETUG-17 trial (NCT00667069) comparing adjuvant versus salvage RT combined with 6 months of hormonal therapy. The estimated enrolment is 718 patients, and the primary endpoint is event-free survival (including biochemical progression) at 5 years.

Finally, the RAVES (radiotherapy adjuvant versus early salvage) trial (NCT00860652) has been activated by the Tasman Radiation Oncology Group (TROG) comparing adjuvant versus salvage RT (64 Gy) without hormonal treatment. The estimated enrollment is 470 patients, and the primary endpoint is biochemical failure.

Until results of these trials become available, the optimal timing and dose of postoperative RT and the value of additional hormonal therapy remain unknown.

Nevertheless, based on evaluation of risk factors for biochemical or clinical failures coming from previous retrospective analysis and three recent randomized trials, most patients with R1, pT3 disease may be offered immediate postoperative RT $[10,12,13]$. Besides, patients with preoperative PSA values of more than $10 \mathrm{ng} / \mathrm{mL}$ and a preoperative PSA velocity of $>2 \mathrm{ng} / \mathrm{mL}$ per year may also benefit from immediate adjuvant RT in terms of improved biochemical control, but this has not been proven by randomized trials $[3,4,12,14,41]$. For all the other patients carrying less pronounced risk factors for tumor recurrence, it seems more reasonable to balance the superior initial quality of life and the lower risk of clinical or PSA recurrence in favour of salvage RT. A score algorithm or nomograms may help in decision making $[6,9,42]$ using risk factors for recurrence as seminal vesicle infiltration, Gleason Score, and pre-RT PSAvalue.

On the other hand, the natural course and life expectancy of men besides prostate cancer have to be considered, with its enormous global inequality [43]. With a realistic life expectancy of less than 5 years, further treatment should not be offered in the adjuvant situation, and even with a life expectancy of up to 8 years, salvage RT seems to be appropriate.

Thereby, it should be remembered that it needs about 8 years from biochemical recurrence to the development of a clinically measurable progression [6].

\section{Conclusions}

The use of adjuvant RT after RP in patients with adverse risk factors has demonstrated improved biochemical control and overall survival. However, there is a relevant risk of overtreatment as patients might be included who are cured by surgery alone. We recommend to offer adjuvant RT to all patients with $\mathrm{R} 1$ resection and $\mathrm{pT} 3$ disease and to also consider preoperative PSA values of more than $10 \mathrm{ng} / \mathrm{mL}$ and a preoperative PSA velocity of $>2 \mathrm{ng} / \mathrm{mL}$ per year as additional risk factors for tumor recurrence.

Alternatively, patients can be treated with salvage RT in the event of biochemical relapse, especially when they are carrying less dominant risk factors for tumor recurrence. It is recommended that such salvage RT should be performed as early as possible, preferably with PSA values below $0.5 \mathrm{ng} /$ $\mathrm{mL}$, and although it was shown to be most effective in patients with adverse risk factors, it should not be withhold from any definite subgroup of patients with biochemical recurrent disease. The optimal dose and timing of postoperative RT is subject of national and international phase III trials. Outside of clinical trials, 60-64 Gy should be used in the immediate postoperative setting and $64-72 \mathrm{~Gy}$ in the salvage setting, dependent on the absence or presence of macroscopic recurrence. Patients with biochemical relapse after RP should be treated within clinical trials to answer open questions on dose and timing as soon as possible.

\section{Conflict of Interests}

The authors have no actual or potential conflict of interests related to this paper. There are no financial disclosures from any author.

\section{References}

[1] M. Han, A. W. Partin, M. Zahurak, S. Piantadosi, J. I. Epstein, and P. C. Walsh, "Biochemical (prostate specific antigen) recurrence probability following radical prostatectomy for clinically localized prostate cancer," Journal of Urology, vol. 169, no. 2, pp. 517-523, 2003.

[2] J. F. Ward and J. W. Moul, "Rising prostate-specific antigen after primary prostate cancer therapy," Nature Clinical Practice Urology, vol. 2, no. 4, pp. 174-182, 2005.

[3] C. L. Amling, M. L. Blute, E. J. Bergstralh, T. M. Seay, J. Slezak, and H. Zincke, "Long-term hazard of progression after radical prostatectomy for clinically localized prostate cancer: continued risk of biochemical failure after 5 years," Journal of Urology, vol. 164, no. 1, pp. 101-105, 2000.

[4] P. A. Kupelian, J. Katcher, H. S. Levin, and E. A. Klein, "Stage T1-2 prostate cancer: a multivariate analysis of factors affecting biochemical and clinical failures after radical prostatectomy," International Journal of Radiation Oncology Biology Physics, vol. 37, no. 5, pp. 1043-1052, 1997.

[5] F. Pinto, T. Prayer-Galetti, M. Gardiman et al., "Clinical and pathological characteristics of patients presenting with biochemical progression after radical retropubic prostatectomy for pathologically organ-confined prostate cancer," Urologia Internationalis, vol. 76, no. 3, pp. 202-208, 2006.

[6] C. R. Pound, A. W. Partin, M. A. Eisenberger, D. W. Chan, J. D. Pearson, and P. C. Walsh, "Natural history of progression after 
PSA elevation following radical prostatectomy," Journal of the American Medical Association, vol. 281, no. 17, pp. 1591-1597, 1999.

[7] S. F. Slovin, A. S. Wilton, G. Heller, and H. I. Scher, "Time to detectable metastatic disease in patients with rising prostatespecific antigen values following surgery or radiation therapy," Clinical Cancer Research, vol. 11, no. 24, pp. 8669-8673, 2005.

[8] L. H. Klotz, "PSA recurrence: definitions, PSA kinetics, and identifying patients at risk," The Canadian Journal of Urology, vol. 13, supplement 2, pp. 43-47, 2006.

[9] A. J. Stephenson, P. T. Scardino, M. W. Kattan et al., "Predicting the outcome of salvage radiation therapy for recurrent prostate cancer after radical prostatectomy," Journal of Clinical Oncology, vol. 25, no. 15, pp. 2035-2041, 2007.

[10] M. Bolla, H. Van Poppel, L. Collette et al., "Postoperative radiotherapy after radical prostatectomy: a randomised controlled trial (EORTC trial 22911)," The Lancet, vol. 366, no. 9485, pp. 572-578, 2005.

[11] I. M. Thompson Jr., C. M. Tangen, J. Paradelo et al., "Adjuvant radiotherapy for pathologically advanced prostate cancer: a randomized clinical trial," Journal of the American Medical Association, vol. 296, no. 19, pp. 2329-2335, 2006.

[12] T. Wiegel, D. Bottke, U. Steiner et al., "Phase III postoperative adjuvant radiotherapy after radical prostatectomy compared with radical prostatectomy alone in pT3 prostate cancer with postoperative undetectable prostate-specific antigen: ARO 9602/AUO AP 09/95," Journal of Clinical Oncology, vol. 27, no. 18, pp. 2924-2930, 2009.

[13] I. M. Thompson, C. M. Tangen, J. Paradelo et al., "Adjuvant radiotherapy for pathological T3N0M0 prostate cancer significantly reduces risk of metastases and improves survival: long-term followup of a randomized clinical trial," Journal of Urology, vol. 181, no. 3, pp. 956-962, 2009.

[14] T. H. Van Der Kwast, M. Bolla, H. Van Poppel et al., "Identification of patients with prostate cancer who benefit from immediate postoperative radiotherapy: EORTC 22911," Journal of Clinical Oncology, vol. 25, no. 27, pp. 4178-4186, 2007.

[15] C. M. Moinpour, K. A. Hayden, J. M. Unger et al., "Healthrelated quality of life results in pathologic stage $\mathrm{C}$ prostate cancer from a Southwest Oncology Group trial comparing radical prostatectomy alone with radical prostatectomy plus radiation therapy," Journal of Clinical Oncology, vol. 26, no. 1, pp. 112-120, 2008.

[16] M. V. Meng, K. Shinohara, G. D. Grossfeld, and P. R. Carroll, "Local therapy for recurrent prostate cancer," in Prostate Cancer: Principles and Practice, P. W. Kantoff, P. R. Carroll, and A. V. D'Amico, Eds., pp. 307-316, Lippincott Williams and Wilkins, Philadelphia, Pa, USA, 2002.

[17] B. J. Trock, M. Han, S. J. Freedland et al., "Prostate cancerspecific survival following salvage radiotherapy vs observation in men with biochemical recurrence after radical prostatectomy," Journal of the American Medical Association, vol. 299, no. 23, pp. 2760-2769, 2008.

[18] R. Choo, G. Hruby, J. Hong et al., “(IN)-efficacy of salvage radiotherapy for rising PSA or clinically isolated local recurrence after radical prostatectomy," International Journal of Radiation Oncology Biology Physics, vol. 53, no. 2, pp. 269-276, 2002.

[19] T. Wiegel, G. Lohm, D. Bottke et al., "Achieving an undetectable PSA after radiotherapy for biochemical progression after radical prostatectomy is an independent predictor of biochemical outcome-results of a retrospective study," International Journal of Radiation Oncology Biology Physics, vol. 73, no. 4, pp. 1009-1016, 2009.
[20] D. Neuhof, T. Hentschel, M. Bischof, G. Sroka-Perez, M. Hohenfellner, and J. Debus, "Long-term results and predictive factors of three-dimensional conformal salvage radiotherapy for biochemical relapse after prostatectomy," International Journal of Radiation Oncology Biology Physics, vol. 67, no. 5, pp. 1411-1417, 2007.

[21] C. Catton, M. Gospodarowicz, P. Warde et al., "Adjuvant and salvage radiation therapy after radical prostatectomy for adenocarcinoma of the prostate," Radiotherapy and Oncology, vol. 59, no. 1, pp. 51-60, 2001.

[22] O. K. MacDonald, S. E. Schild, S. Vora et al., "Salvage radiotherapy for men with isolated rising PSA or locally palpable recurrence after radical prostatectomy: do outcomes differ?" Urology, vol. 64, no. 4, pp. 760-764, 2004.

[23] M. S. Katz, M. J. Zelefsky, E. S. Venkatraman, Z. Fuks, A. Hummer, and S. A. Leibel, "Predictors of biochemical outcome with salvage conformal radiotherapy after radical prostatectomy for prostate cancer," Journal of Clinical Oncology, vol. 21, no. 3, pp. 483-489, 2003.

[24] A. J. Stephenson, S. F. Shariat, M. J. Zelefsky et al., "Salvage radiotherapy for recurrent prostate cancer after radical prostatectomy," Journal of the American Medical Association, vol. 291, no. 11, pp. 1325-1332, 2004.

[25] M. S. Anscher, R. Clough, and R. Dodge, "Radiotherapy for a rising prostate-specific antigen after radical prostatectomy: the first 10 years," International Journal of Radiation Oncology Biology Physics, vol. 48, no. 2, pp. 369-375, 2000.

[26] J. R. Bernard, S. J. Buskirk, M. G. Heckman et al., "Salvage radiotherapy for rising prostate-specific antigen levels after radical prostatectomy for prostate cancer: dose-response analysis," International Journal of Radiation Oncology Biology Physics, vol. 76, no. 3, pp. 735-740, 2010.

[27] G. De Meerleer, V. Fonteyne, S. Meersschout et al., "Salvage intensity-modulated radiotherapy for rising PSA after radical prostatectomy," Radiotherapy and Oncology, vol. 89, no. 2, pp. 205-213, 2008.

[28] L. V. Do, T. M. Do, R. Smith, and R. G. Parker, "Postoperative radiotherapy for carcinoma of the prostate: impact on both local control and distant disease-free survival," American Journal of Clinical Oncology, vol. 25, no. 1, pp. 1-8, 2002.

[29] C. R. King and M. T. Spiotto, "Improved outcomes with higher doses for salvage radiotherapy after prostatectomy," International Journal of Radiation Oncology Biology Physics, vol. 71, no. 1, pp. 23-27, 2008.

[30] S. Loeb, K. A. Roehl, D. P. Viprakasit, and W. J. Catalona, "Long-term rates of undetectable PSA with initial observation and delayed salvage radiotherapy after radical prostatectomy," European Urology, vol. 54, no. 1, pp. 88-96, 2008.

[31] J. F. Pazona, M. Han, S. A. Hawkins, K. A. Roehl, and W. J. Catalona, "Salvage radiation therapy for prostate specific antigen progression following radical prostatectomy: 10-Year outcome estimates," Journal of Urology, vol. 174, no. 4, pp. 1282-1286, 2005.

[32] T. M. Pisansky, T. F. Kozelsky, R. P. Myers et al., "Radiotherapy for isolated serum prostate specific antigen elevation after prostatectomy for prostate cancer," Journal of Urology, vol. 163, no. 3, pp. 845-850, 2000.

[33] H. G. Van Der Poel, L. Moonen, and S. Horenblas, "Sequential treatment for recurrent localized prostate cancer," Journal of Surgical Oncology, vol. 97, no. 5, pp. 377-382, 2008.

[34] P. Poortmans, A. Bossi, K. Vandeputte et al., "Guidelines for target volume definition in post-operative radiotherapy for prostate cancer, on behalf of the EORTC Radiation Oncology 
Group," Radiotherapy and Oncology, vol. 84, no. 2, pp. 121127, 2007.

[35] G. A. Viani, E. J. Stefano, and S. L. Afonso, "Higher-thanconventional radiation doses in localized prostate cancer treatment: a meta-analysis of randomized, controlled trials," International Journal of Radiation Oncology Biology Physics, vol. 74, no. 5, pp. 1405-1418, 2009.

[36] C. R. King and D. S. Kapp, "Radiotherapy after prostatectomy: is the evidence for dose escalation out there?" International Journal of Radiation Oncology Biology Physics, vol. 71, no. 2, pp. 346-350, 2008.

[37] C. Cozzarini, F. Montorsi, C. Fiorino et al., "Need for high radiation dose $(\geq 70 \mathrm{~Gy})$ in early postoperative irradiation after radical prostatectomy: a single-institution analysis of 334 high-risk, node-negative patients," International Journal of Radiation Oncology Biology Physics, vol. 75, no. 4, pp. 966-974, 2009.

[38] M. Feng, A. L. Hanlon, T. M. Pisansky et al., "Predictive factors for late genitourinary and gastrointestinal toxicity in patients with prostate cancer treated with adjuvant or salvage radiotherapy," International Journal of Radiation Oncology Biology Physics, vol. 68, no. 5, pp. 1417-1423, 2007.

[39] G. P. Swanson, M. A. Hussey, C. M. Tangen et al., "Predominant treatment failure in postprostatectomy patients is local: analysis of patterns of treatment failure in SWOG 8794," Journal of Clinical Oncology, vol. 25, no. 16, pp. 2225-2229, 2007.

[40] M. C. Abramowitz and A. Pollack, "Postprostatectomy radiation therapy for prostate cancer," Seminars in Radiation Oncology, vol. 18, no. 1, pp. 15-22, 2008.

[41] M. N. Simmons, A. J. Stephenson, and E. A. Klein, "Natural history of biochemical recurrence after radical prostatectomy: risk assessment for secondary therapy," European Urology, vol. 51, no. 5, pp. 1175-1184, 2007.

[42] S. J. Buskirk, T. M. Pisansky, S. E. Schild et al., "Salvage radiotherapy for isolated prostate specific antigen increase after radical prostatectomy: evaluation of prognostic factors and creation of a prognostic scoring system," Journal of Urology, vol. 176, no. 3, pp. 985-990, 2006.

[43] P. Day, J. Pearce, and D. Dorling, "Twelve worlds: a geodemographic comparison of global inequalities in mortality," Journal of Epidemiology and Community Health, vol. 62, no. 11, pp. 1002-1007, 2008. 


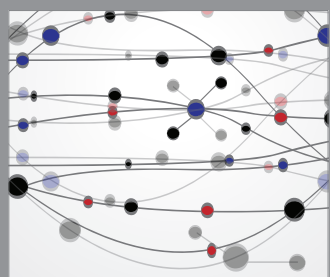

The Scientific World Journal
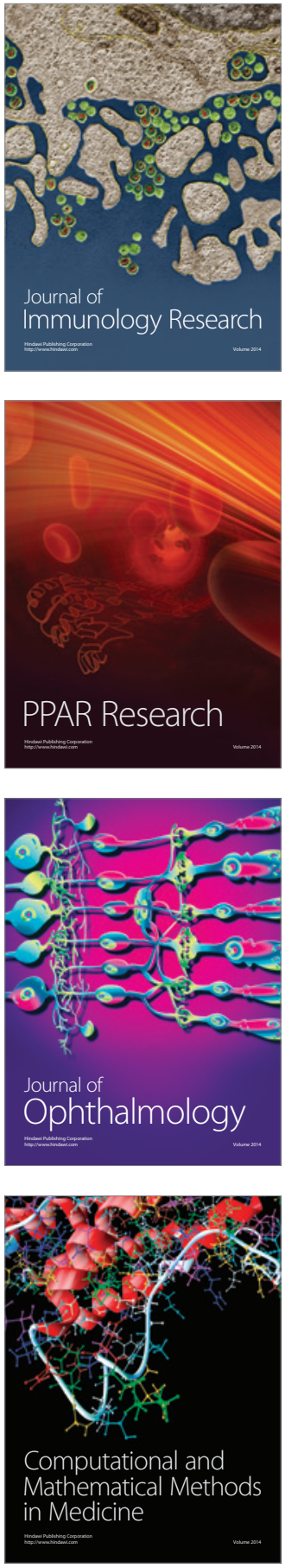

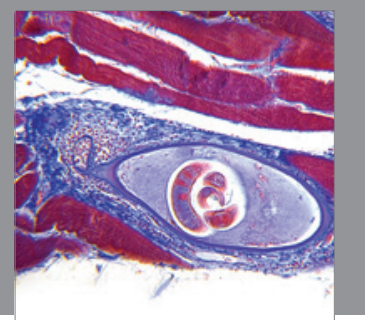

Gastroenterology

Research and Practice
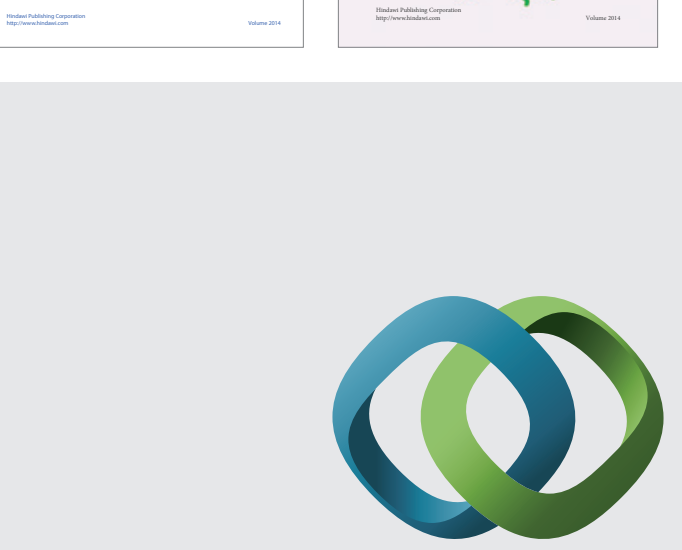

\section{Hindawi}

Submit your manuscripts at

http://www.hindawi.com
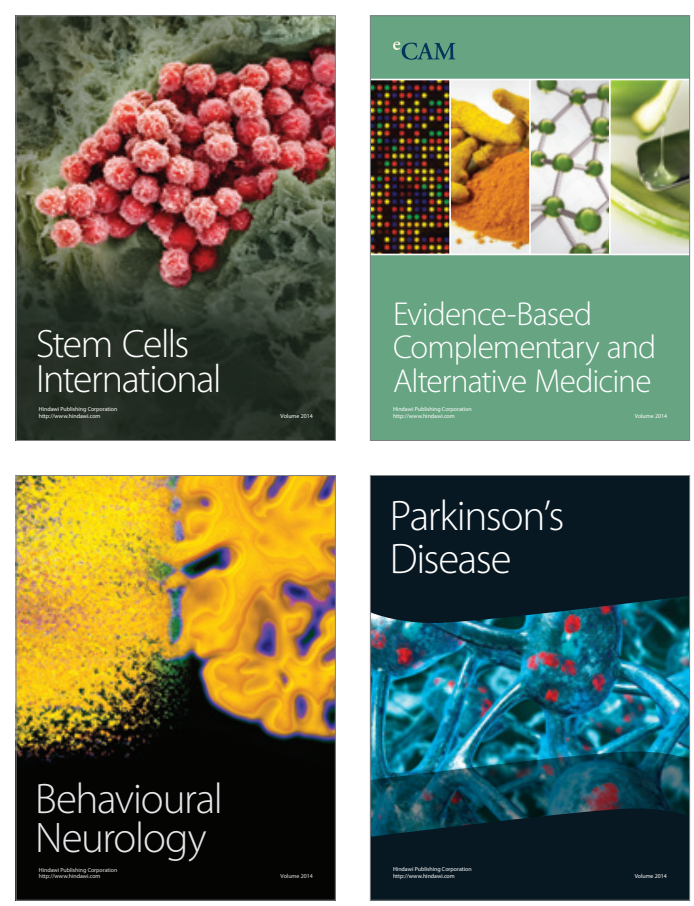

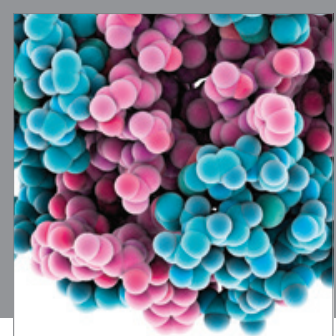

Journal of
Diabetes Research

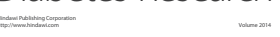

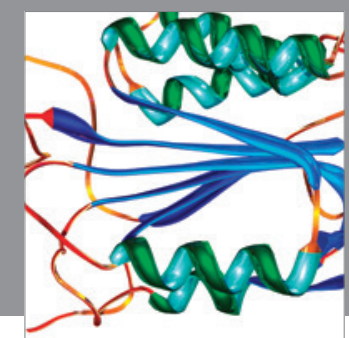

Disease Markers
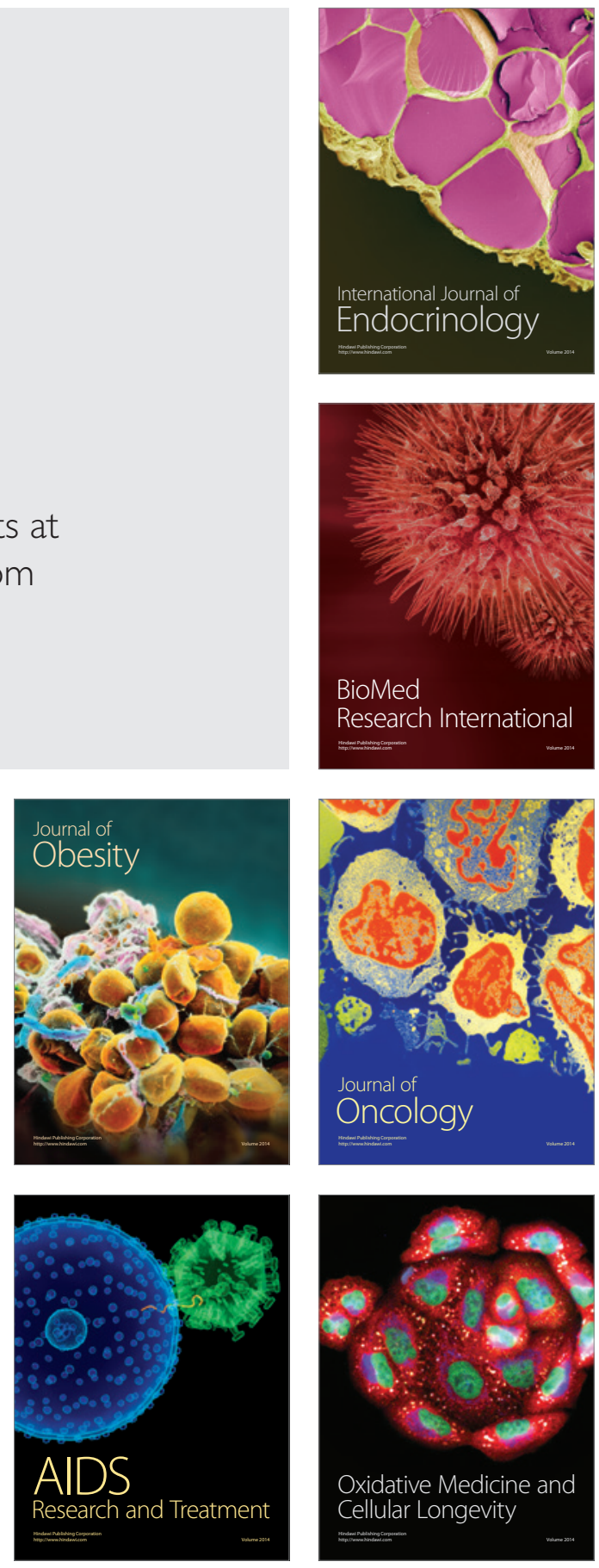